\title{
Treatment with propranolol for infantile hemangiomas: A case series of 106 infants
}

\author{
SHANG-BIN LI, GUANG-QI XU, FENG GAO and RAN HUO \\ Department of Aesthetic, Plastic and Burn Surgery, Shandong Provincial Hospital Affiliated to Shandong University, \\ Jinan, Shandong 250021, P.R. China
}

Received August 28, 2014; Accepted April 28, 2015

DOI: 10.3892/etm.2015.2485

\begin{abstract}
The aim of the present study was to investigate the clinical benefit and side effects of propranolol treatment in 106 children with infantile hemangiomas (IHs). A retrospective chart review was conducted on all children who attended the clinic between September 16, 2009 and November 11, 2013. Propranolol was administered in a progressive schedule reaching 1.0-1.5 mg/kg/day, divided into three doses. Demographic data, clinical features, imaging, treatment regimens and outcomes were investigated. Any adverse effects following medication were evaluated and managed accordingly. Preliminary analysis of the data showed the inclusion of 106 children (71 female and 35 male) with a mean age and weight at onset of treatment of 5.1 months and $7.3 \mathrm{~kg}$, respectively. All 106 patients responded positively to treatment. Side effects that required intervention and/or close monitoring included diarrhea $(n=10)$, hypotension $(n=7)$, nightmares $(n=2)$, agitation $(n=1)$ and cold extremities $(n=1)$. No long-term adverse effects were observed in any of the patients. In conclusion, propranolol administered orally at $1.0-1.5 \mathrm{mg} / \mathrm{kg} /$ day had a rapid therapeutic effect for resolving IHs with few complications.
\end{abstract}

\section{Introduction}

Infantile hemangiomas (IHs) are soft-tissue neoplasms that commonly occur in infancy and affect $4-10 \%$ of children, with girls being more susceptible than boys (1). At birth, the hemangiomas have an inconspicuous appearance; the lesions then undergo rapid proliferation, normally within the first year, and reach a plateau phase. When the child reaches $\sim 2$ years of age, many hemangiomas will begin a process of spontaneous involution (2); however, the majority

Correspondence to: Dr Ran Huo, Department of Aesthetic, Plastic and Burn Surgery, Shandong Provincial Hospital Affiliated to Shandong University, 324 Jingwu Road, Jinan, Shandong 250021, P.R. China

E-mail: huoran@medmail.com.cn

Key words: propranolol, infants, hemangiomas, side effects of the affected children will exhibit telangiectatic cutaneous vessels, fibrous fatty tissue or scar formations as a residue of the lesion $(3,4)$.

Traditionally, treatment options for IHs include watching and waiting, corticosteroids, laser surgery, cryosurgery, interferon- $\alpha$, vincristine and surgical resection (5-7); however. a number of these interventions have significant drawbacks or side effects and are inconsistently efficacious (8).

In 2008, Léauté-Labrèze et al (9) reported a notable response following the treatment of IHs with propranolol, a lipophilic, nonselective $\beta$-blocker that is widely used in pediatric cardiology for the treatment of numerous conditions, including cardiac dysrhythmias, hypertension, congestive heart failure and Tetralogy of Fallot (10). This serendipitous effect of propranolol was described for two children with facial hemangiomas, following which numerous studies worldwide were initiated to investigate the use of propranolol therapy in children with hemangiomas $(8,11-14)$. Propranolol has subsequently been widely accepted as the first-line treatment for IHs; however, the optimal dosage and duration of treatment remain unclear. The aim of the present study, therefore, was to investigate the therapeutic effects of propranolol treatment and the associated side effects in 106 children with IHs.

\section{Patients and methods}

Patient selection. The present study was a retrospective review of the treatment of IHs with propranolol, which was provided by Tianjin Lisheng Pharmaceutical Co., Ltd. (Tianjin, China), between September 16, 2009 and November 11, 2013 at the Department of Aesthetic, Plastic and Burn Surgery of the Provincial Hospital affiliated to Shandong University (Jinan, China). For inclusion in the study, the following criteria were used: i) IHs were clinically diagnosed using criteria provided by the International Society for the Study of Vascular Anomalies in 1996 (15,16); ii) infants aged >1 month of age; iii) propranolol administered for the treatment of IHs; and iv) follow-up period of $>2$ months. A treatment guideline was designed based on the known side effects of propranolol in collaboration with pediatric cardiologists, endocrinologists and dermatologists. All patients were treated as inpatients. Informed consent was obtained from the parents for the off-label use of propranolol and for the publication of the study. Ethical approval for the 
Table I. Exclusion criteria for a patient.

\begin{tabular}{lccc}
\hline $\begin{array}{l}\text { Age } \\
\text { (months) }\end{array}$ & $\begin{array}{c}\text { Systolic } \\
\text { pressure }(\mathrm{mmHg})\end{array}$ & $\begin{array}{c}\text { Diastolic } \\
\text { pressure (mmHg) }\end{array}$ & $\begin{array}{c}\text { Heart rate (waking and } \\
\text { resting state, bpm) }\end{array}$ \\
\hline $1-6$ & 70 & 30 & 100 \\
$7-12$ & 90 & 35 & 90 \\
$>12$ & 85 & 40 & 80 \\
\hline
\end{tabular}

study was provided by the Medical Ethics Committee of the Provincial Hospital affiliated to Shandong University.

Protocol. All patients were subjected to the following protocol prior to propranolol treatment: Clinical examination with palpation (to evaluate the surface tension of the lesion), photography (to record the location, size and color of the hemangioma) and ultrasonographic examination (to determine the maximal thickness of the lesion). A GE Vivid 7 ultrasound system (GE Healthcare, Holten, Norway) was used for the ultrasonographic examination. Electrocardiology (cardiofax Q ECG-9130P; Nihon Kohden Corp., Tokyo, Japan), blood pressure (HEM-7071 digital automatic hemadynamometer; Omron, Kyoto, Japan), heart rate and blood glucose (SureStep ${ }^{\mathrm{TM}}$ blood glucose monitoring system; LifeScan, Inc., Milpitas, CA, USA) evaluations were also conducted for exclusionary purposes. The patient was excluded based on the criteria for electrocardiology, blood pressure, heart rate and blood glucose evaluation results shown in Table I and described below: i) any abnormality of an electrocardiogram confirmed by a pediatrician, ii) the diastolic and/or systolic pressure being lower than that in the table at different ages, iii) the heart rate being lower than that in the table at different ages or iv) the fasting blood glucose being $<3.9 \mathrm{mmol} / 1$ or $>5.6 \mathrm{mmol} / 1$.

The starting dosage was $0.5 \mathrm{mg} / \mathrm{kg} / \mathrm{day}$, divided into three daily doses, and this was increased over a 4-day period to $1.0-1.5 \mathrm{mg} / \mathrm{kg} / \mathrm{day}$. During the first 5 days, blood pressure, heart rate and fasting glucose levels were monitored 1.5-2.0 $\mathrm{h}$ after starting the propranolol treatment. In the absence of side effects, treatment was continued at home, and the patients were re-evaluated after 2 weeks, followed by an evaluation once every 4-8 weeks. During treatment, the dose was adjusted for increased weight. At each clinic visit, the effect of the treatment was determined, and possible adverse events were documented. The criteria of propranolol withdrawal were as follows: Maximal improvement of lesion achieved (8) and/or the age of patients reached 13-15 months.

\section{Results}

Patient characteristics. Data for the demographics of the patients and the lesions are collectively summarized in Tables II and III, respectively. The study included 106 patients (71 female and 35 male), with an average age of 5.1 months (range, 1.0-14.0 months) and a mean weight of $7.3 \mathrm{~kg}$ (range, $3.5-12.5 \mathrm{~kg}$ ) at the time of the initial propranolol treatment, with a total of 127 IHs. The IHs in 62 patients $(58.5 \%)$ had been present since birth. The anatomical locations of the IHs
Table II. Patient data at initial presentation.

\begin{tabular}{lc}
\hline Item & Value \\
\hline Total, n (\%) & $106(100.0)$ \\
Gender & \\
Male, $\mathrm{n}(\%)$ & $35(33.0)$ \\
Female, $\mathrm{n}(\%)$ & $71(67.0)$ \\
Male/female ratio & $1 / 2$ \\
Presentation, $\mathrm{n}(\%)$ & \\
Single lesion & $86(81.1)$ \\
Multiple lesions & $20(18.9)$ \\
Onset, $\mathrm{n}(\%)$ & $62(58.5)$ \\
Since birth & $44(41.5)$ \\
After birth & $5.1(1.0-14.0)$ \\
Age in months at initial propranolol & \\
treatment, mean (range) & $7.3(3.5-12.5)$ \\
Weight in kg at initial propranolol & \\
treatment, mean (range) & \\
\hline
\end{tabular}

are listed in Table III. The mean duration of treatment was 8.8 months (range, 3-18 months). Of the 127 IHs, 16 (12.6\%) were ulcerating at the time of the initial propranolol treatment. The anatomical region most commonly affected by ulceration was the head and neck $(12 / 16,75 \%)$. Other affected sites were anogenital $(2 / 16,12.5 \%)$ and the extremities $(2 / 16$, $12.5 \%)$. Seven patients had been treated with oral prednisone, 29 with intravenous pingyangmycin and 11 with pulsed dye laser therapy prior to receiving propranolol. No significant electrocardiogram or fasting glucose abnormalities were observed.

Effect of treatment with propranolol. All 106 patients demonstrated a rapid improvement following propranolol treatment. Between 1 and 4 weeks after treatment initiation, all of the lesions had changed in appearance from bright red to purple with areas of gray. Upon palpation, a considerable reduction in the tension at the surface was noted. Following a marked initial response to the propranolol administration, continued improvements in the color and thickness of the IHs were observed (Fig. 1). Thirteen children remained on propranolol treatment at the time of manuscript preparation.

Side effects of propranolol treatment for IH. Adverse effects associated with propranolol were suspected in 18 patients $(17.0 \%, 18 / 106)$. Of those 18 children, $10(9.4 \%, 10 / 106)$ 


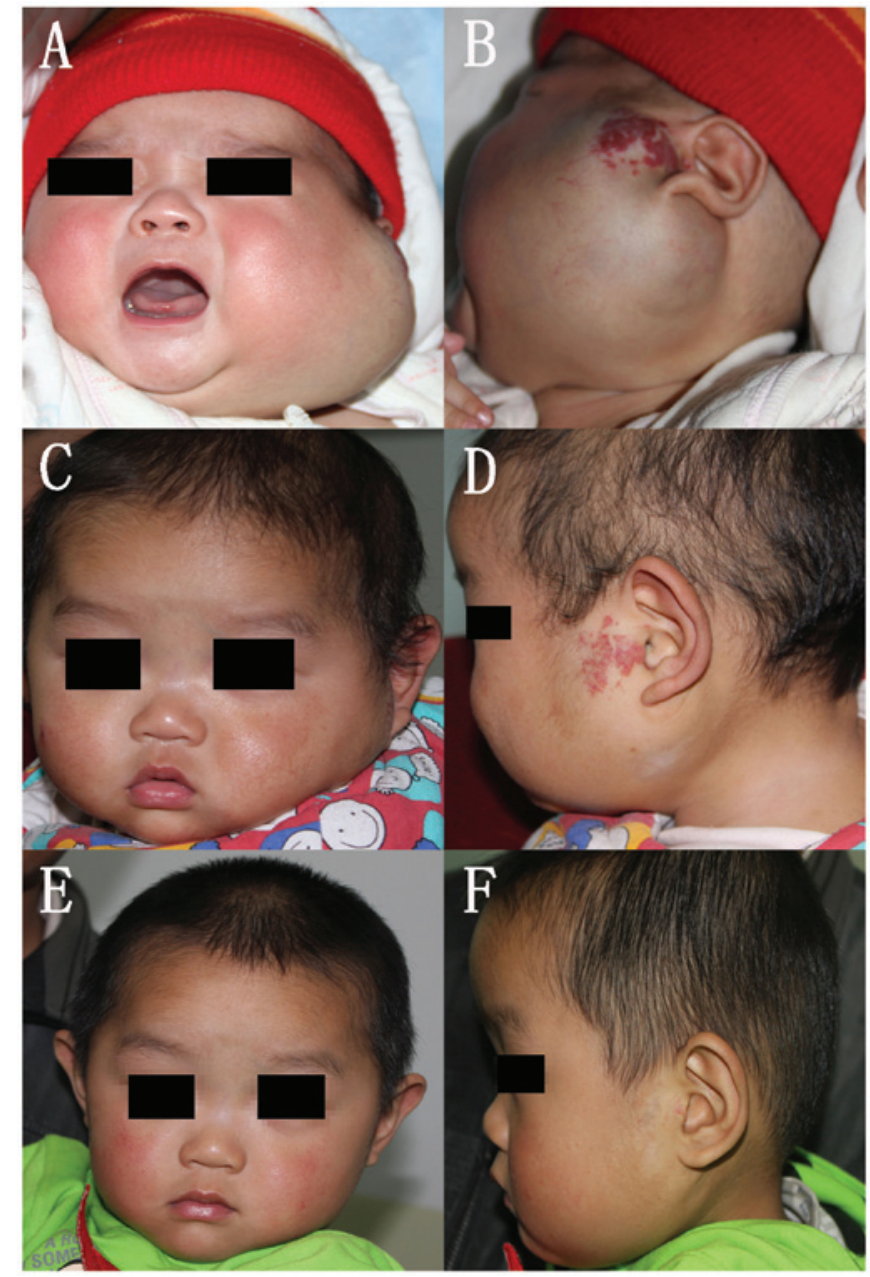

Figure 1. Infantile hemangioma on the left parotid region (A and B) before treatment with propranolol; (C and D) after 8 months of follow-up (7.5 months of treatment); and (E and F) 1.5-years after the end of treatment.

developed transient diarrhea during their propranolol treatment and $7(6.6 \%, 7 / 106)$ experienced transient asymptomatic hypotension during a propranolol loading dose (3-4 days after commencing treatment). In addition, parents reported nightmares in 2 infants $(1.9 \%, 2 / 106)$, gastroesophageal reflux in 2 children $(1.9 \%, 2 / 106)$, agitation in 1 patient $(0.9 \%, 1 / 106)$ and cold extremities in 1 patient $(0.9 \%, 1 / 106)$.

\section{Discussion}

In the present study, a rapid halt in lesion progression and evidence of regression in the majority of the examined $\mathrm{IH}$ cases were observed. The exact mechanism of propranolol action on IHs is poorly understood. Early effects are believed to originate from vasoconstrictive effects on the capillaries in the IHs. Intermediate effects are attributed to the decreased expression of vascular endothelial growth factor and fibroblast growth factor, resulting in growth arrest. Long-term effects may be caused by the apoptosis of capillary endothelial cells, resulting in tumor regression (17).

In this retrospective study, 106 children treated with propranolol for IHs exhibited varying degrees of tumor regression. This, in combination with results from other
Table III. Data for the IHs at initial presentation.

\begin{tabular}{lc}
\hline Item & $\mathrm{n}(\%)$ \\
\hline Total & $106(100.0)$ \\
IH type & \\
Superficial & $63(59.4)$ \\
Deep & $11(10.4)$ \\
Compound/mixed & $32(30.2)$ \\
Sites (location) of IHs, $\mathrm{n}=127$ & \\
Head & $76(59.8)$ \\
Scalp & $8(6.3)$ \\
Cheek and forehead & $18(14.2)$ \\
Periorbital eyelids & $12(9.4)$ \\
Lips and tongue & $16(12.6)$ \\
Nose & $10(7.9)$ \\
Ear & $3(2.4)$ \\
Parotid region & $7(5.5)$ \\
Neck & $2(1.6)$ \\
Limbs & $23(18.1)$ \\
Trunk & $17(13.4)$ \\
Perineum & $11(8.7)$ \\
Ulceration & $16(12.6)$ \\
\hline
\end{tabular}

$\mathrm{IH}$, infantile hemangioma.

published reports $(17,18)$, suggests that propranolol can serve as a first-line treatment for IHs $(12,19-21)$; however, there is not a generally accepted consensus on the appropriate dosage of propranolol or the duration of treatment. Several reports have shown successful results with doses ranging between 0.5 and $4 \mathrm{mg} / \mathrm{kg} / \mathrm{day}$, administered in two or three divided doses $(19,20,22)$. In the present study, the mean dose of propranolol was $1.0 \mathrm{mg} / \mathrm{kg} /$ day (highest dose, $1.5 \mathrm{mg} / \mathrm{kg} /$ day), which was less than the average level used in other published reports $(20,21,23,24)$. This dose of propranolol resulted in a rapid improvement for all patients examined. In order to avoid rebound growth, the optimal duration of propranolol treatment for IHs should cover the majority, if not all, of the proliferative phase. According to Chang et al (25), the overall growth stage of IH is typically completed by 9 months of age, and involution begins at 1 year of age (range, 9-14 months). The criteria for propranolol withdrawal in the present study were therefore set to comprise the achievement of the maximal lesion improvement and/or an age of 13-15 months. Using these principles, no further rebound growth was observed.

Ulceration is the most common complication of IHs, possibly affecting $5-13 \%$ of children $(1,26)$. It is typically painful and can lead to infection, bleeding and scarring, all of which may lead to functional problems and cosmetic disfiguration, affecting the quality of life of the infant and the infant's family. In this study, $16(16 / 127,12.6 \%)$ children had an ulcerating $\mathrm{IH}$ at the time of starting propranolol treatment. These children had received oral propranolol and concomitant 
wound dressings, and topical and/or oral antibiotics. Fifteen ulcers healed within a median time of 2.8 weeks (range, 2-4 weeks) with 1 outlier at 12 weeks.

To date, the reported potential side effects of propranolol treatment for IHs have included hypoglycemia, bronchospasm, bradycardia, hypotension, hyperkalemia, gastrointestinal discomfort/reflux and fatigue; however, these adverse events are all rare at dosages $<2 \mathrm{mg} / \mathrm{kg} /$ day (27). In the present study, a dose of $1.5 \mathrm{mg} / \mathrm{kg} /$ day was optimal, whereas the incidence of complications in children markedly increased at a higher dose.

In $9.4 \%$ of patients $(10 / 106)$, propranolol therapy was discontinued due to transient diarrhea during treatment, and treatment with an anti-diarrheic was required. Given that infantile diarrhea is common, further study is required to determine whether this is a true association.

Propranolol treatment was also associated with a decrease in blood pressure. Seven patients had transient asymptomatic hypotension that occurred during a propranolol loading dose (3-4 days after commencing treatment) and resolved following dosage reduction. In addition, 1 patient experienced cold extremities, which were resolved before the subsequent dose. Serious sequelae suggestive of organ hypoperfusion due to hypotension were not observed. In addition, parents reported the occurrence of nightmares in 2 infants, gastroesophageal reflux in 2 children and agitation in 1 patient; these side effects were all resolved before the subsequent dose.

In conclusion, the oral administration of propranolol (1.0-1.5 mg/kg/day) had a rapid therapeutic effect in all IH cases in the present study, with few complications. This approach could lead to the considerable shortening of the natural course of IHs. Further comparative, randomized studies are required to determine the safety and efficacy of propranolol.

\section{References}

1. Frieden IJ, Haggstrom AN, Drolet BA, et al: Infantile hemangiomas: Current knowledge, future directions. Proceedings of a research workshop on infantile hemangiomas, April 7-9, 2005 Bethesda, Maryland, USA. Pediatr Dermatol 22: 383-406, 2005.

2. Zimmermann AP, Wiegand S, Werner JA and Eivazi B: Propranolol therapy for infantile haemangiomas: Review of the literature. Int J Pediatr Otorhinolaryngol 74: 338-342, 2010.

3. Eivazi B, Ardelean M, Bäumler W, et al: Update on hemangiomas and vascular malformations of the head and neck. Eur Arch Otorhinolaryngol 266: 187-197, 2009.

4. Werner JA, Dünne AA, Lippert BM and Folz BJ: Optimal treatment of vascular birthmarks. Am J Clin Dermatol 4: 745-756, 2003.

5. Amer TA, Elwakil TF and Elbasiouny MS: Open rhinoplasty for treatment of nasal tip haemangioma. Eur J Plast Surg 30: 67-73, 2007.

6. Kono T, Sakurai H, Groff WF, et al: Comparison study of a traditional pulsed dye laser versus a long-pulsed dye laser in the treatment of early childhood hemangiomas. Lasers Surg Med 38: 112-115, 2006.
7. Marler JJ and Mulliken JB: Current management of hemangiomas and vascular malformations. Clin Plast Surg 32: 99-116, 2005.

8. Sans V, de la Roque ED, Berge J, et al: Propranolol for severe infantile hemangiomas: Follow-up report. Pediatrics 124: e423-e431, 2009.

9. Léauté-Labrèze C, Dumas de la Roque E, Hubiche T, Boralevi F, Thambo JB and Taïeb A: Propranolol for severe hemangiomas of infancy. N Engl J Med 358: 2649-2651, 2008.

10. Love JN and Sikka N: Are 1-2 tablets dangerous? Beta-blocker exposure in toddlers. J Emerg Med 26: 309-314, 2004.

11. Denoyelle F, Leboulanger N, Enjolras O, Harris R, Roger G and Garabedian EN: Role of Propranolol in the therapeutic strategy of infantile laryngotracheal hemangioma. Int J Pediatr Otorhinolaryngol 73: 1168-1172, 2009.

12. Holmes WJ, Mishra A, Gorst C and Liew SH: Propranolol as first-line treatment for infantile hemangiomas. Plast Reconstr Surg 125: 420-421, 2010.

13. Jephson CG,Manunza F, Syed S, Mills NA,Harper J and Hartley BE: Successful treatment of isolated subglottic haemangioma with propranolol alone. Int J Pediatr Otorhinolaryngol 73: 1821-1823, 2009.

14. Michel JL and Patural H: Response to oral propranolol therapy for ulcerated hemangiomas in infancy. Arch Pediatr 16: 1565-1568, 2009 (In French).

15. Blei F: Basic science and clinical aspects of vascular anomalies. Curr Opin Pediatr 17: 501-509, 2005.

16. Chang MW: Updated classification of hemangiomas and other vascular anomalies. Lymphat Res Biol 1: 259-265, 2003.

17. Storch CH and Hoeger PH: Propranolol for infantile haemangiomas: insights into the molecular mechanisms of action. $\mathrm{Br} \mathrm{J}$ Dermatol 163: 269-274, 2010.

18. Peridis S, Pilgrim G, Athanasopoulos I and Parpounas K: A meta-analysis on the effectiveness of propranolol for the treatment of infantile airway haemangiomas. Int J Pediatr Otorhinolaryngol 75: 455-460, 2011.

19. Schiestl C, Neuhaus K, Zoller S, et al: Efficacy and safety of propranolol as first-line treatment for infantile hemangiomas. Eur J Pediatr 170: 493-501, 2011.

20. Holmes WJ, Mishra A, Gorst C and Liew SH: Propranolol as first-line treatment for rapidly proliferating infantile haemangiomas. J Plast Reconstr Aesthet Surg 64: 445-451, 2011.

21. Denoyelle F and Garabédian EN: Propranolol may become first-line treatment in obstructive subglottic infantile hemangiomas. Otolaryngol Head Neck Surg 142: 463-464, 2010.

22. de Graaf M, Breur JM, Raphaël MF, Vos M, Breugem CC and Pasmans SG: Adverse effects of propranolol when used in the treatment of hemangiomas: A case series of 28 infants. J Am Acad Dermatol 65: 320-327, 2011.

23. Xiao Q, Li Q, Zhang B and Yu W: Propranolol therapy of infantile hemangiomas: efficacy, adverse effects, and recurrence. Pediatr Surg Int 29: 575-581, 2013.

24. Szychta P, Stewart K and Anderson W: Treatment of infantile hemangiomas with propranolol: clinical guidelines. Plast Reconstr Surg 133: 852-862, 2014.

25. Chang LC, Haggstrom AN, Drolet BA, et al: Growth characteristics of infantile hemangiomas: Implications for management. Pediatrics 122: 360-367, 2008.

26. Kim HJ, Colombo M and Frieden IJ: Ulcerated hemangiomas: Clinical characteristics and response to therapy. J Am Acad Dermatol 44: 962-972, 2001.

27. Buckmiller LM, Munson PD, Dyamenahalli U, Dai Y and Richter GT: Propranolol for infantile hemangiomas: Early experience at a tertiary vascular anomalies center. Laryngoscope 120: 676-681, 2010. 